\title{
Comparison of the effect and clinical value in general anesthesia and combined spinal-epidural anesthesia in elderly patients undergoing hip arthroplasty
}

\author{
HUANHUI ZHONG, YONGDONG WANG, YIQUN WANG and BAIYUN WANG \\ Department of Anesthesiology, Affiliated Nanhua Hospital, University of South China, \\ Hengyang, Hunan 421002, P.R. China
}

Received November 19, 2018; Accepted March 18, 2019

DOI: $10.3892 /$ etm.2019.7465

\begin{abstract}
Effect and clinical value in general anesthesia and combined spinal-epidural anesthesia in elderly patients undergoing hip arthroplasty were compared. One hundred and six patients with hip arthroplasty in the Affiliated Nanhua Hospital, University of South China from May 2013 to July 2015 were selected as the research subjects, including 50 patients in the study group who received combined spinalepidural anesthesia by ondansetron hydrochloride tablets combined with spinal-epidural puncture kit, and 56 patients in the control group who received general anesthesia by fastinduced endotracheal intubation. Retrospective analysis was performed in terms of anesthesia effect, complete block time, anesthesia onset time, hemodynamic parameters at different time points before and after the surgery, and adverse reactions after the surgery. The study group had a statistically shorter onset time and a statistically shorter complete block time than the control group $(\mathrm{P}<0.05)$. No significant difference in the heart rate, systolic blood pressure or diastolic blood pressure before the surgery in the two groups was shown $(\mathrm{P}>0.05)$; the heart rate, systolic blood pressure, and diastolic blood pressure in the study group 20 min after the start of the operation and $15 \mathrm{~min}$ before the end of the operation were significantly higher those in the control group $(\mathrm{P}<0.05)$; the adverse reactions such as venous thrombosis, pulmonary infection, and nausea and vomiting in the study group were fewer than those in the control group $(\mathrm{P}<0.05)$. For elderly patients with fracture surgery, both the general anesthesia and the combined spinalepidural anesthesia can maintain a good anesthesia effect, but the combined spinal-epidural anesthesia can shorten the
\end{abstract}

Correspondence to: Dr Baiyun Wang, Department of Anesthesiology, Affiliated Nanhua Hospital, University of South China, 336 Dongfeng South Road, Hengyang, Hunan 421002, P.R. China

E-mail: bt72vk@163.com; 2549732620@qq.com

Key words: general anesthesia, combined spinal-epidural anesthesia, hip arthroplasty, clinical value onset time and has less impact on the patient's hemodynamic parameters and less incidence of complications, thus worthy of clinical promotion.

\section{Introduction}

Hip fracture is the most devastating result of osteoporosis (1). Hip fracture in the elderly population, due to its frequent adverse outcomes and high mortality, has become a major medical and public health problem (2-5). According to statistics, $5 \%$ of men and $10 \%$ of women suffer from hip fractures during their lifetime (6). The mortality rate in the first year after injury of the hip in elderly patients can reach up to $20 \%(5,6)$. According to the manual of the Brazilian Society of Geriatrics and Gerontology in 2008, approximately 5\% of falls have caused fractures, the most common is a cone fracture. The incidence of hip fractures is increasing in many countries (7), so is the risk of subsequent hip fracture after a fall of elderly people (8). In most cases, fractures have a serious impact on the patient's physical ability and longevity (9). Both the combined spinal-epidural anesthesia and the general anesthesia are common anesthesia methods for hip arthroplasty. Due to the decreased physiological compensatory capacity and the poor cardiopulmonary function of the elderly, the risk of surgery and anesthesia increases in elderly patients. Rashid and his coworkers demonstrated that anesthesia should be customized for the individual needs of the patient (10). The choice of anesthesia in various surgical operations remains controversial (11). Therefore, it is important to choose an anesthesia method that ensures the efficacy of anesthesia while reducing the irritation to the patient and improving the safety of the operation. This study mainly analyzed the effect and clinical value of the general anesthesia and the combined spinal-epidural anesthesia in elderly patients undergoing hip arthroplasty.

\section{Patients and methods}

General information. One hundred and six elderly patients who received hip arthroplasty in the department of orthopedics in the Affiliated Nanhua Hospital, University of South China (Hengyang, China) from May 2013 to July 2015 were 
Table I. Comparison of general data between the two groups of patients [n (\%)].

\begin{tabular}{|c|c|c|c|c|}
\hline Group & Study group $(\mathrm{n}=50)$ & Control group $(n=56)$ & $\chi^{2} / \mathrm{t}$ value & P-value \\
\hline Sex & & & 0.052 & 0.820 \\
\hline Male & 23 & 27 & & \\
\hline Female & 27 & 29 & & \\
\hline Age (year) & & & 0.149 & 0.700 \\
\hline$<75$ & 25 & 29 & & \\
\hline$\geq 75$ & 25 & 27 & & \\
\hline BMI $\left(\mathrm{kg} / \mathrm{m}^{2}\right)$ & & & 0.004 & 0.947 \\
\hline$\leq 22$ & 22 & 25 & & \\
\hline$>22$ & 28 & 31 & & \\
\hline Heart rate $\left(\right.$ beat $\left.\cdot \min ^{-1}\right)$ & $80.64 \pm 5.14$ & $79.48 \pm 4.84$ & 1.173 & 0.243 \\
\hline Systolic blood pressure (mmHg) & $130.24 \pm 8.84$ & $128.51 \pm 8.97$ & 0.998 & 0.321 \\
\hline Diastolic blood pressure (mmHg) & $86.24 \pm 5.16$ & $86.54 \pm 5.24$ & 0.296 & 0.768 \\
\hline Drinking situation & & & 0.210 & 0.647 \\
\hline Yes & 21 & 26 & & \\
\hline No & 29 & 30 & & \\
\hline Smoking situation & & & 0.013 & 0.911 \\
\hline Yes & 20 & 23 & & \\
\hline No & 30 & 33 & & \\
\hline
\end{tabular}

selected as the research subjects and were divided into the study group (50 patients) and the control group (56 patients) according to different anesthesia methods. The study group consisted of 23 males and 27 females, aged from 60 to 87 $(72.5 \pm 6.8)$ years who received combined spinal-epidural anesthesia by ondansetron hydrochloride tablets combined with spinal-epidural puncture kit, and the control group consisted of 27 males and 29 females, aged from 61 to 88 (75.4 \pm 7.2) years who received general anesthesia by fastinduced endotracheal intubation. No significant differences existed in terms of sex, age, BMI and other general data between the two groups $(\mathrm{P}>0.05)$. All the patients and their families signed the informed consent and cooperated with medical staff to complete relevant medical treatment. This study was approved by the Ethics Committee of the Affiliated Nanhua Hospital, University of South China. The general information is shown in Table I.

Methods. For patients in both groups, before the anesthesia, the intravenous access was established on the upper limb of the patient, and the detection instrument was connected to the patient to monitor vital signs such as breathing, blood pressure, and heart rate. Patients in the study group received combined spinal-epidural anesthesia by ondansetron hydrochloride tablets combined with spinal-epidural puncture kit, and the specific procedures were as follows: the patient was placed lying on the uninjured side, with the L3-4 gap as the puncture point, and then was anesthetized by the ondansetron hydrochloride tablets combined with spinal-epidural puncture kit. After the successful puncture, $7.5-10 \mathrm{mg}$ of $0.5 \%$ bupivacaine was injected into the subarachnoid space in $40 \mathrm{sec}$, and the epidural tube was placed. For patients whose level of anesthesia did not reach the 8 th thoracic level 16 min after the drug administration, a total of $7.75 \mathrm{ml}$ of $2 \%$ lidocaine was additionally injected from the epidural tube at two separate times $(6.54 \mathrm{ml}$ for the first time and $1.21 \mathrm{ml}$ for the second time). Surgery was started after the spinal anesthesia was stabilized, and 2\% lidocaine was added intermittently during the operation according to the situation.

Patients in the control group received general anesthesia by fast-induced endotracheal intubation, and the specific methods were as follows: mask oxygenation and endotracheal intubation were performed on patients with the use of ondansetron at a dose of $0.1 \mathrm{mg}$ for per kilogram of the patient's weight, fentanyl at a dose of $2 \mu \mathrm{g}$ for per kilogram of the patient's weight, carbazole diazepam at a dose of $0.1 \mathrm{mg}$ for per kilogram of the patient's weight, etomidate at a dose of $0.2 \mathrm{mg}$ for per kilogram of the patient's weight. After 3 min of continuous intubation, the respiration was regulated to a satisfatory state, and then a constant use of fentanyl combined with propofol followed, with a 1:2,000 ratio of the two.

Inclusion and exclusion criteria. All research subjects received hip arthroplasty in the department of orthopedics in the Affiliated Nanhua Hospital, University of South China. Patients with severe impairment in mental function or cognitive function were excluded from the study, so were patients with other cardiovascular diseases, liver dysfunction, and renal dysfunction, and patients allergic to the drugs used.

Observation criteria and evaluation criteria. Comparisons between the two groups were made in terms of the patient's anesthesia effect, complete block time, anesthesia onset time, the hemodynamic parameters at different time points 


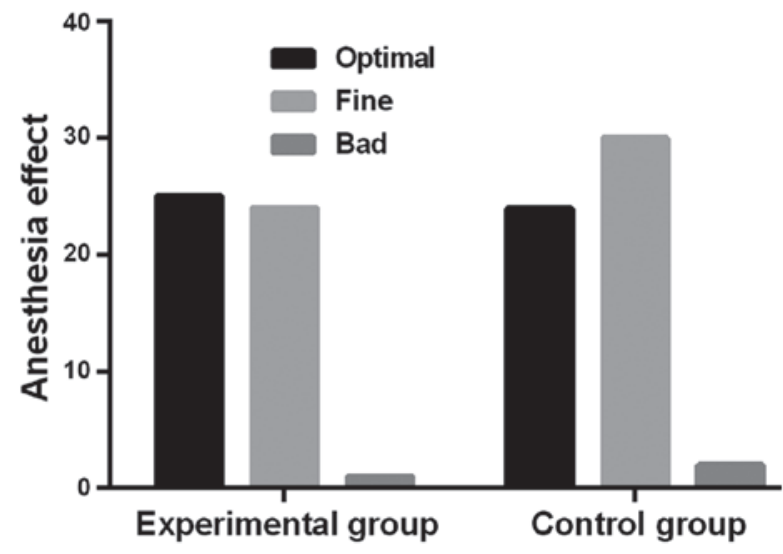

Figure 1. Comparison of the anesthesia effects between the two groups. The study group had a superior anesthesia effect than the control group, but the difference was not statistically significant $\left(\chi^{2}=0.683, P>0.05\right)$.

of the patient's surgery, and postoperative adverse reactions. Evaluation criteria for anesthesia effect: excellent effect: patients were calm, with great state of muscle relaxation and no pain symptoms, in no need for adjuvant drugs; good effect: patients were in fairly good state of muscle relaxation, with occasional pain and temporary need for adjuvant drugs; poor effect: patients were not calm, with poor state of muscle relaxation and pain symptoms, in need for adjuvant drugs.

Statistical methods. The data were analyzed and processed using SPSS 19.6 statistical software [Boyi (Beijing) Information Technology Co., Ltd., Beijing, China]. The patient's basic enumeration data was expressed as a percentage [n (\%)] and analyzed by the Chi-square test. The complete block time, anesthesia onset time, and hemodynamic parameters were expressed as the mean \pm standard deviation (mean $\pm \mathrm{SD}$ ) and calculated using the t-test, and the statistical significance was set at $\mathrm{P}<0.05$.

\section{Results}

Comparison of anesthetic effects between the two groups. The rate of excellent and good anesthesia effect in the study group was $98.00 \%$, with 25 patients receiving excellent effect, 24 patients receiving good effect and 1 patient receiving poor effect. The rate of excellent and good anesthesia effect in the control group was $96.43 \%$, with 24 patients receiving excellent effect, 30 patients receiving good effect and 2 patients receiving poor effect. The anesthetic effect of the study group was better than that of the control group, but the difference was not statistically significant $\left(\chi^{2}=0.683, P>0.05\right)$ (Fig. 1$)$.

Comparison of complete block time and anesthesia onset time. The study group had an onset time of $20.8 \pm 4.8 \mathrm{sec}$ and a complete block time of $8.9 \pm 2.8 \mathrm{~min}$, shorter than the onset time $(61.5 \pm 17.5 \mathrm{sec})$ and the complete block time $(13.9 \pm 2.5 \mathrm{~min})$ in the control group, and the difference was statistically significant $(\mathrm{P}<0.05)($ Table II).

Comparison of hemodynamic parameters at different time points in the operation between the two groups. The indexes of
Table II. Comparison of complete block time and anesthesia onset time (mean $\pm \mathrm{SD})$.

\begin{tabular}{lcc}
\hline Group & $\begin{array}{c}\text { Anesthesia } \\
\text { onset time } \\
(\mathrm{sec})\end{array}$ & $\begin{array}{c}\text { Complete } \\
\text { block time } \\
(\mathrm{min})\end{array}$ \\
\hline Study group $(\mathrm{n}=50)$ & $20.8 \pm 4.8$ & $8.9 \pm 2.8$ \\
Control group $(\mathrm{n}=56)$ & $61.5 \pm 17.5$ & $13.9 \pm 2.5$ \\
t value & 15.86 & 10.14 \\
P-value & $<0.001$ & $<0.001$ \\
\hline
\end{tabular}

heart rate, systolic blood pressure, and diastolic blood pressure before the operation in the study group were $80.64 \pm 5.14$, $130.24 \pm 8.84$ and $86.24 \pm 5.16$, respectively; while heart rate, systolic blood pressure, and diastolic blood pressure before the operation in the control group were 79.48 $\pm 4.84,128.51 \pm 8.97$, and $86.54 \pm 5.24$, respectively. The differences of the heart rates, systolic blood pressures, and diastolic blood pressures before the operation between the two groups were not statistically significant $(\mathrm{P}>0.05)$. The heart rate, systolic blood pressure, and diastolic blood pressure indexes $20 \mathrm{~min}$ after the start of the operation in the study group were $74.84 \pm 4.27$ and $123.47 \pm 6.74$, $83.07 \pm 4.23$, respectively, greatly higher than the heart rate (63.17 \pm 4.54$)$, the systolic blood pressure $(111.27 \pm 6.48)$ and the diastolic blood pressure $(73.64 \pm 4.64) 20 \mathrm{~min}$ after the start of the operation in the control group, and the differences were statistically different $(\mathrm{P}<0.05)$. The heart rate, systolic blood pressure, and diastolic blood pressure indexes $15 \mathrm{~min}$ before the end of the operation in the study group were $76.94 \pm 4.61$, $126.54 \pm 6.87$, and $85.84 \pm 4.61$, respectively, while the heart rate, systolic blood pressure, and diastolic blood pressure indexes of the control group $15 \mathrm{~min}$ before the end of the operation in the control group were $68.41 \pm 4.61,115.64 \pm 6.51,77.56 \pm 4.81$. The heart rate, systolic blood pressure, and diastolic blood pressure index $15 \mathrm{~min}$ before the end of the operation in the study group were significantly higher than that of the control group, and the difference was statistically significant $(\mathrm{P}<0.05)$ (Table III).

Comparison of postoperative adverse reactions between the two groups. The study group had lower rate of adverse reactions than the control group, with 1 case of venous thrombosis, 1 case of pulmonary infection, and 1 case of nausea and vomiting in the study group, while 7 cases of venous thrombosis, 8 cases of pulmonary infection, and 8 cases of nausea and vomiting in the control group, and the difference was statistically significant $(\mathrm{P}<0.05)$ (Table IV).

\section{Discussion}

Hip fracture is one of the most common injuries in the elderly, and is associated with complications and mortality (12-14). Approximately 3 million cases of hip fractures occur each year in the United States, and this number is expected to grow with the increase of elderly population (15). According to relevant reports, early surgery can improve the treatment outcomes, including hospitalization time, pulmonary function, and the ability to return to independent life $(16,17)$. Therefore, 
Table III. Hemodynamic parameters at different time points in the operation in the two groups (mean \pm SD).

\begin{tabular}{|c|c|c|c|c|c|c|}
\hline \multirow[b]{2}{*}{ Group } & \multicolumn{3}{|c|}{ Study group $(n=50)$} & \multicolumn{3}{|c|}{ Control group $(n=56)$} \\
\hline & $\begin{array}{l}\text { Before the } \\
\text { experiment }\end{array}$ & $\begin{array}{l}20 \text { min after } \\
\text { the start of } \\
\text { the operation }\end{array}$ & $\begin{array}{l}15 \text { min before } \\
\text { the end of } \\
\text { the operation }\end{array}$ & $\begin{array}{l}\text { Before the } \\
\text { experiment }\end{array}$ & $\begin{array}{l}20 \text { min after } \\
\text { the start of } \\
\text { the operation }\end{array}$ & $\begin{array}{l}15 \text { min before } \\
\text { the end of } \\
\text { the operation }\end{array}$ \\
\hline Heart rate $\left(\right.$ beat $\left.\cdot \min ^{-1}\right)$ & $80.64 \pm 5.14$ & $74.84 \pm 4.27$ & $76.94 \pm 4.61$ & $79.48 \pm 4.84$ & $63.17 \pm 4.54^{\mathrm{a}}$ & $68.41 \pm 4.61^{\mathrm{a}}$ \\
\hline Systolic blood pressure (mmHg) & $130.24 \pm 8.84$ & $123.47 \pm 6.74$ & $126.54 \pm 6.87$ & $128.51 \pm 8.97$ & $111.27 \pm 6.48^{\mathrm{a}}$ & $115.64 \pm 6.51^{\mathrm{a}}$ \\
\hline Diastolic blood pressure ( $\mathrm{mmHg}$ ) & $86.24 \pm 5.16$ & $83.07 \pm 4.23$ & $85.84 \pm 4.61$ & $86.54 \pm 5.24$ & $73.64 \pm 4.64^{\mathrm{a}}$ & $77.56 \pm 4.81^{\mathrm{a}}$ \\
\hline
\end{tabular}

${ }^{\text {aP }}<0.05$ compared with the study group.

Table IV. Comparison of postoperative adverse reactions between the two groups $[\mathrm{n}(\%)]$.

\begin{tabular}{lccc}
\hline Group & $\begin{array}{c}\text { Venous } \\
\text { thrombosis }\end{array}$ & $\begin{array}{c}\text { Pulmonary } \\
\text { infection }\end{array}$ & $\begin{array}{c}\text { Nausea and } \\
\text { vomiting }\end{array}$ \\
\hline Study group $(\mathrm{n}=50)$ & $1(2.00)$ & $1(2.00)$ & $1(2.00)$ \\
Control group $(\mathrm{n}=56)$ & $7(12.50)$ & $8(14.29)$ & $8(14.29)$ \\
$\chi^{2}$ value & 4.174 & 5.132 & 4.174 \\
P-value & 0.041 & 0.024 & 0.041 \\
\hline
\end{tabular}

it is a wise choice to perform surgical treatment on elderly patients with hip fracture immediately after admission. However, early surgery is not feasible for patients with physiological instability and high risk (18). Joint arthroplasty is often considered a successful treatment beneficial to pain relief and the improvement of quality of life (19). In addition to the quality of surgical treatment, a suitable anesthesia method in accordance with the actual situation of the patient in the specific surgery process is also very important, which will directly affect the patient's surgical quality and prognosis. Thus, a carefully selected anesthesia method according to the situation of the patient is needed to ensure a good surgical result and prognosis. This study compared the efficacy and clinical value of the general anesthesia and the combined spinal-epidural anesthesia in elderly patients undergoing hip arthroplasty.

This study included 106 elderly patients with hip arthroplasty in the department of orthopedics in the Affiliated Nanhua Hospital, University of South China as the research subjects. Patients in the study group underwent a combined spinal-epidural anesthesia by ondansetron hydrochloride tablets combined with spinal-epidural puncture kit, and patients in the control group received a general anesthesia by fast-induced endotracheal intubation. First, the anesthetic effects of the study group and the control group were compared, and the anesthetic effect of the study group was proved to be better than that of the control group, but with no statistically significant difference $(\mathrm{P}>0.05)$. No relevant data so far has pointed out whether there is an improvement in performance of the general anesthesia compared with the combined spinal-epidural anesthesia or the opposite.
At present, both local anesthesia and general anesthesia are performed during the operation on the elderly. However, the final choice of anesthesia comes from the anesthesiologist's experience and preferences, as well as discussions with patients and their caregivers (20). Next, this study compared the complete block time and the anesthesia onset time and found that the onset time and complete block time of the study group were shorter than the control group, and the differences were statistically significant $(\mathrm{P}<0.05)$. Studies have shown that $(21)$ local anesthesia is currently selected during the surgery to shorten the time of possible impact of anesthesia residues on patients. The direct injection of anesthesia into the local nerve innervation of the operation area that can quickly block the generation and transmission of nerve impulses has a positive effect on shortening the anesthesia time and improving the safety of surgery. After that, the hemodynamic parameters of the two groups before the surgery, $20 \mathrm{~min}$ after the start of the operation, and $15 \mathrm{~min}$ before the end of the operation were compared. The results showed that the two groups were not statistically different in the preoperative heart rate, systolic blood pressure, and diastolic blood $(\mathrm{P}>0.05)$; the heart rate, systolic blood pressure, and diastolic blood pressure index of the study group 20 min after the start of the operation were statistically significantly higher than that of the control group $(\mathrm{P}<0.05)$; the heart rate, systolic blood pressure, and diastolic blood pressure index of the study group $15 \mathrm{~min}$ before the end of the operation were significantly higher than the control group, and the difference was statistically significant $(\mathrm{P}<0.05)$.

No previous study on the hemodynamics parameters before and after hip arthroplasty has been reported. Studies have shown that (22) general anesthesia makes patients unconscious through the use of various intravenous and/or inhaled drugs, which causes fewer cerebrovascular accidents and shorter anesthesia time compared with local anesthesia. Other studies have shown that (23), the more adverse reactions of general anesthesia compared with spinal anesthesia in total hip arthroplasty may be associated with the increased incidence of intraoperative hypotension aroused by general anesthesia, which serves as an excellent support for the view of this study. Finally, comparison of the adverse reactions between the two groups was performed and revealed fewer adverse reactions such as venous thrombosis, pulmonary infection, nausea and vomiting in the study group than in the control group, with a statistical difference $(\mathrm{P}<0.05)$. Patients 
undergoing hip arthroplasty are mainly elderly people who usually suffer from cardiovascular diseases, diabetes and other senile diseases, with a relatively slow blood flow and hypercoagulable blood due to long-term bed rest and joint damage before the surgery. Traction of vessels due to repeated dislocation, restoration and twist of the limbs during the long operation time may cause damage to the intima, promote the production of inflammatory cytokines, activate the exogenous coagulation pathway, and arouse thrombosis. Studies have proven (24) the marginal advantage of local anesthesia in the risk of deep vein thrombosis compared with general anesthesia in patients with hip fracture. White and his team (25) pointed out local anesthesia had a better effect than the general anesthesia to inhibit pulmonary complications, which agrees with the findings of this study.

In this study, despite every possible effort to avoid errors caused by human factors, the small number of research subjects was likely to cause some contingency and deviations in the results.

In summary, the combined spinal-epidural anesthesia by ondansetron hydrochloride tablets combined with spinalepidural puncture kit had a better anesthesia effect than the general anesthesia by fast-induced endotracheal intubation. Both anesthesia methods could maintain a good anesthesia sate, but combined spinal-epidural anesthesia by ondansetron hydrochloride tablets combined with spinal-epidural puncture kit could shorten the complete block time and the anesthesia onset time and have less impact on the patient's hemodynamic parameters, with a lower incidence of complications.

\section{Acknowledgements}

Not applicable.

\section{Funding}

No funding was received.

\section{Availability of data and materials}

The datasets used and/or analyzed during the present study are available from the corresponding author on reasonable request.

\section{Authors' contributions}

HZ and YoW conceived and designed the study. YiW collected the patient data. HZ and BW analyzed and interpreted the data regarding the elderly patients undergoing hip arthroplasty. $\mathrm{HZ}$ was a major contributor in writing the manuscript. BW reviewed the manuscript. All authors read and approved the final manuscript.

\section{Ethics approval and consent to participate}

The study was approved by the Ethics Committee of Affiliated Nanhua Hospital, University of South China (Hengyang, China). Patients who participated in this research had complete clinical data. Signed informed consents were obtained from the patients or the guardians.

\section{Patient consent for publication}

Not applicable.

\section{Competing interests}

The authors declare that they have no competing interests.

\section{References}

1. Cauley JA: Public health impact of osteoporosis. J Gerontol A Biol Sci Med Sci 68: 1243-1251, 2013.

2. Haentjens P, Magaziner J, Colón-Emeric CS, Vanderschueren D, Milisen K, Velkeniers B and Boonen S: Meta-analysis: Excess mortality after hip fracture among older women and men. Ann Intern Med 152: 380-390, 2010.

3. Richmond J, Aharonoff GB, Zuckerman JD and Koval KJ: Mortality risk after hip fracture. J Orthop Trauma 17: 53-56, 2003.

4. Bliuc D, Nguyen ND, Milch VE, Nguyen TV, Eisman JA and Center JR: Mortality risk associated with low-trauma osteoporotic fracture and subsequent fracture in men and women. JAMA 301: 513-521, 2009.

5. Hung LW, Tseng WJ, Huang GS and Lin J: High short-term and long-term excess mortality in geriatric patients after hip fracture: A prospective cohort study in Taiwan. BMC Musculoskelet Disord 15: 151, 2014.

6. Gullberg B, Johnell $\mathrm{O}$ and Kanis JA: World-wide projections for hip fracture. Osteoporos Int 7: 407-413, 1997.

7. Lee KH, Ha YC, Lee YK, Kang H and Koo KH: Frequency, risk factors, and prognosis of prolonged delirium in elderly patients after hip fracture surgery. Clin Orthop Relat Res 469: 2612-2620, 2011.

8. Chen XW, Shi JW, Yang PS and Wu ZQ: Preoperative plasma leptin levels predict delirium in elderly patients after hip fracture surgery. Peptides 57: 31-35, 2014.

9. Heyes GJ, Tucker A, Marley D and Foster A: Predictors for readmission up to 1 year following hip fracture. Arch Trauma Res 4: e27123, 2015

10. Rashid RH, Shah AA, Shakoor A and Noordin S: Hip fracture surgery: Does type of anesthesia matter? BioMed Res Int 2013: 252356, 2013

11. Gupta N: Delirium: another factor when considering type of anesthetic for hip fracture surgery in adults. BMJ 349: g4871, 2014.

12. Buecking B, Bohl K, Eschbach D, Bliemel C, Aigner R, BalzerGeldsetzer M, Dodel R, Ruchholtz S and Debus F: Factors influencing the progress of mobilization in hip fracture patients during the early postsurgical period? - A prospective observational study. Arch Gerontol Geriatr 60: 457-463, 2015.

13. Caillet P, Klemm S, Ducher M, Aussem A and Schott AM: Hip fracture in the elderly: A re-analysis of the EPIDOS study with causal Bayesian networks. PLoS One 10: e0120125, 2015.

14. Cook WL, Schiller C, McAllister MM, Hanson HM, Brasher PM, Donaldson MG, Macri E, Preto R, Guy P and Ashe MC: Feasibility of a follow-up hip fracture clinic. J Am Geriatr Soc 63: 598-599, 2015

15. Hawkes D, Baxter J, Bailey C, Holland G, Ruddlesdin J, Wall A and Wykes P: Improving the care of patients with a hip fracture: A quality improvement report. BMJ Qual Saf 24: 532-538, 2015.

16. Sherrington C, Lord SR and Herbert RD: A randomized controlled trial of weight-bearing versus non-weight-bearing exercise for improving physical ability after usual care for hip fracture. Arch Phys Med Rehabil 85: 710-716, 2004.

17. Boylan MR, Rosenbaum J, Adler A, Naziri Q and Paulino CB: Hip fracture and the weekend effect: Does weekend admission affect patient outcomes? Am J Orthop (Belle Mead NJ) 44: 458-464, 2015

18. Clague JE, Craddock E, Andrew G, Horan MA and Pendleton N: Predictors of outcome following hip fracture. Admission time predicts length of stay and in-hospital mortality. Injury 33: 1-6, 2002.

19. Rolfson O, Rothwell A, Sedrakyan A, Chenok KE, Bohm E, Bozic KJ and Garellick G: Use of patient-reported outcomes in the context of different levels of data. J Bone Joint Surg Am 93 (Suppl 3): 66-71, 2011 
20. Li T, Yeung J, Li J, Zhang Y, Melody T, Gao Y, Wang Y, Lian Q and Gao F; RAGA-Delirium Investigators: Comparison of regional with general anaesthesia on postoperative delirium (RAGA-delirium) in the older patients undergoing hip fracture surgery: Study protocol for a multicentre randomised controlled trial. BMJ Open 7: e016937, 2017.

21. White SM, Moppett IK and Griffiths R: Outcome by mode of anaesthesia for hip fracture surgery. An observational audit of 65,535 patients in a national dataset. Anaesthesia 69: 224-230, 2014.

22. White SM, Griffiths R, Holloway J and Shannon A: Anaesthesia for proximal femoral fracture in the UK: First report from the NHS Hip Fracture Anaesthesia Network. Anaesthesia 65 243-248, 2010.

23. Borghi B, Casati A, Iuorio S, Celleno D, Michael M, Serafini P, Pusceddu A and Fanelli G; Study Group on Orthopedic Anesthesia of the Italian Society of Anesthesia, Analgesia, and Intensive Care (SIAARTI): Frequency of hypotension and bradycardia during general anesthesia, epidural anesthesia, or integrated epidural-general anesthesia for total hip replacement J Clin Anesth 14: 102-106, 2002.
24. Urwin SC, Parker MJ and Griffiths R: General versus regional anaesthesia for hip fracture surgery: A meta-analysis of randomized trials. Br J Anaesth 84: 450-455, 2000.

25. White SM and Griffiths R: Projected incidence of proximal femoral fracture in England: A report from the NHS Hip Fracture Anaesthesia Network (HIPFAN). Injury 42: 1230-1233, 2011.

(i) (2) This work is licensed under a Creative Commons Attribution-NonCommercial-NoDerivatives 4.0 International (CC BY-NC-ND 4.0) License. 